\title{
Interpersonal Conflict Goals: A Literature Review
}

\author{
David R. Dunaetz \\ Claremont Graduate University
}

\begin{abstract}
Conflict, a process involving perceptions of differences and opposition, is often an undesired but inevitable consequence of social interaction. This review describes the various goals (internal representations of desired states) that can be present in interpersonal conflict. Several streams of research are examined: conflict motivational models which examine the conflicting parties' motives, conflict types which classify conflicts by the parties' conscious focus, and desired outcome models which seek to identify what the parties in a conflict desire to happen. An integrative summary of these streams of research identifies four major categories of conflict goals: content goals, relationship goals, identity goals, and process goals. Further research is needed to clarify the nature of these goals, as well increase our understanding of the relationship between conflict goals, conflict outcomes, and conflict behavior in various contexts. Such research may lead to more constructive conflict management and more satisfying conflict resolution.
\end{abstract}

Key words: conflict, goals, relationship, identity, process

Interpersonal conflicts are among the most difficult parts of life. Although most people would prefer avoiding them, such interactions are inevitable. But interpersonal conflicts do not simply occur randomly. Rather, they are goal based and serve various functions (Coser, 1956). Understanding these goals makes constructive conflict resolution more likely because integrative solutions to problems can be found which may allow each of the parties to meet their goals (Fisher, Ury, \& Patton, 1991; Rahim, 2001). This review summarizes previous research concerning interpersonal conflict goals, identifies four important categories of goals (content goals, relationship goals, identity goals, and process goals), discusses limitations in conflict goal research, and makes recommendations for further research in conflict goals.

In this review, most previous research concerning interpersonal conflict goals will be classified into three streams of research based on the theoretical perspective used. The first will be identified as conflict motivational models (e.g., Pruitt \&
Rubin, 1986; Tjosvold, 1991; Von Neumann, Morgenstern, Kuhn, \& Rubinstein, 1947) which focus on the disputants' motives. These models examine the influence of different motives that individual disputants hold along one or more dimensions. Another stream of research identifies conflict types (Jehn, 1995, 1997b); this approach identifies the participants' conscious focus in the conflict process, which is closely related to their desired outcomes. The third stream of research will be identified as desired outcome models (e.g., Curhan, Elfenbein, \& Xu, 2006; Fisher et al., 1991; Wilmot \& Hocker, 2001) which seeks to directly identify what the participants desire to obtain as a result of the conflict.

This review will begin with definitions of conflict and goals and will then cover the three streams of research. A synthesis of the research will then be presented using four categories to identify conflict goals (content, relationship, identity, and process) along with various subcategories of goals. However, much remains to be explored concerning 
the relationship between these various goals, their relationship to conflict behavior, and their relationship to conflict outcomes (e.g., how the parties evaluate the results of a conflict); several suggestions for future research will be presented.

\section{Definitions}

Having conceptual and functional definitions of the key concepts of conflict and goals will provide a framework in which other concepts may be placed and integrated.

\section{Conflict}

Although conflict research has always held an important place in the fields of social psychology and organizational behavior (e.g., Katz \& Kahn, 1966; Lewin, 1948), there is not yet a consensus as to what conflict is (Tjosvold, 2008). The most important sources of contention concern whether conflict should be viewed as a state or a process. When perceived as a state, conflict is most commonly defined as a perceived incompatibility of interests of two or more parties (e.g., Fisher et al., 1991; Pruitt \& $\mathrm{Kim}, 2004)$; it is conceived of as a state of disagreement or opposition among two or more parties. This definition has been criticized because it assumes that the desired outcomes of the parties are in opposition to each other and that all parties view the state as competitive (Tjosvold, 2008). An alternative definition of conflict as a state focuses on the behaviors of the parties, not their perception of each other; conflict is conceived of as incompatible activities undertaken by two or more parties (Deutsch, 1973; Tjosvold, 2008). From this point of view, two parties in a state of conflict may either cooperate or compete to resolve the conflict by modifying either their own activities or their perceptions of the other party's activities.

Conflict may also be viewed as a process (e.g., Katz \& Kahn, 1966; Pondy, 1967; Van de Vliert, 1997). From this point of view, conflict is defined as the "process that begins when an individual or group perceives differences and opposition between itself and another individual or group about interests and resources, beliefs, values, or practices that matter to them" (de Dreu \& Gelfand, 2008 , p. 6). The process continues with the parties enacting various behaviors which influence the degree to which each party's goals are accomplished which in turn leads to various degrees of satisfaction. The process definition is broader than the various state definitions of conflicts. This definition has the advantage of capturing the dynamic nature of conflicts as the state of the participants and the environment evolve. Process models include both states of latent conflict (an internal state characterized by perceptions of opposition and negative affect) and manifest conflict (a state of observable behaviors which might include destructive aggression or constructive negotiations), as well as the activities that lead from one to the other (typically communication processes; Olekalns, Putnam, Weingart, \& Metcalf, 2008). A simple process model of conflict (de Dreu \& Gelfand, 2008) that includes the transition from internal states based on the parties' perceptions to their external behaviors that often follow can be represented as:

Within-party latent conflict $\rightarrow$ Communication processes $\rightarrow$ Between-party manifest conflict.

Any conflict may consist of several conflict episodes (Pondy, 1967), each of which would be characterized by such a process and could occur in series or in parallel. Conflict resolution occurs when the manifest conflict leads to the end of latent conflict. Unresolved conflict exists as long as manifest conflict does not address the issues in such a way as to end the perceptions which produce latent conflict within one or both of the parties. This process definition of conflict will be used throughout this review because it is more comprehensive and thus allows for a fuller discussion of phenomena that occur in conflicts than when simply examining conflict states.

\section{Goals}

Goals can be defined as an individual's "internal representations of desired states" (Austin \& Vancouver, 1996, p. 338). These desired states may vary with time and are a function of both the person and the environment. They are characterized by equifinality: The desired states may often be achieved by any of several means. Goals may also be arranged hierarchically in mental representations; the achievement of a subgoal may lead to the achievement of a higher level goal. A conflict goal would thus be any mental representation of a desired state that an individual possesses at any point in a conflict process which the individual believes can be achieved through conflict behavior (actions which can influence the conflict process and outcomes e.g., withdrawal or negotiation).

Austin and Vancouver (1996) propose six dimensions along which goals vary, all of which are relevant to conflict dynamics. Goal importance is a rating of anticipated satisfaction of achievement; some conflict goals will be more important than others to an individual and are therefore assumed to be sought after more vigorously. For example, a pastor and a lay leader in a church may be in conflict concerning whether to use traditional or 
contemporary music in the weekly worship service. One may see this as an important issue and fight more vigorously than the other who sees this as a less important goal.

Goal difficulty is a function of effort required to achieve the goal and probability of attaining the goal at that level of effort; the difficulty of conflict goals may influence the effort that an individual is willing to exert. Using the above example, the person who wants the change in music style may perceive change to be unlikely and thus perceive this goal to be very difficult and perhaps not worth the effort required. The person who wishes to maintain the status quo may have a history of helping the organization resist change and thus may consider the goal of maintaining a traditional style an attainable goal if he or she provides enough resistance.

Goal specificity indicates how clearly the accomplishment of a goal may be identified; some conflict goals may be clearly identified as achieved, whereas others are less clear and can prevent the perception of complete conflict resolution. The person who prefers traditional music may not know how to completely distinguish between what he or she likes or dislikes. The distinction between contemporary and traditional may not be clear. If this is the case, the person may not know what possible solutions are acceptable or not, making negotiations more difficult. A lack of goal specificity may also contribute to one or both parties perceiving that satisfactory resolution has been achieved when, in fact, the parties are still not in agreement because none of the issues that led to the conflict have been addressed. Such a perception of a conflict resolution may be sufficient to satisfy both parties in both the short and long term, but if conflict goals become more specific and clearly identified by one or both of the parties, the perception of resolution may be quite ephemeral.

The temporal range of goals can range from milliseconds to multiple generations. The pastor and the lay leader may focus their concerns on the program for next Suday's service or they may focus their concerns on future generations. When focusing on long range goals, the parties are more likely to find common concerns than when focusing on short term goals (Greenhalgh, 1986).

The level of consciousness of goals indicates the degree to which goals are cognitively accessible to a party; many goals may remain subconscious (Bargh, Gollwitzer, Lee-Chai, Barndollar, \& Trotschel, 2001) or difficult to access (Steele, 1988; e.g. the desire for power or affiliation) but may be very influential in conflict processes. One party may subconsciously associate contemporary music with the drug culture and may have a subconscious goal of protecting the church's youth from chemical dependence. The other party may subconsciously link traditional music to being bored in church as a teenager and may have the subconscious goal of making the church services less boring than in previous generations. If the parties are not conscious of these goals, they will find it more difficult to discuss the issues and find common interests than if both parties are conscious of all of their goals.

Goal complexity indicates to what degree one goal is connected to other goals. If a goal is highly connected to other goals, then achieving one goal may influence the conditions required for other goals to be achieved. Complex conflict goals (those which are highly connected to other goals) require greater effort and cooperation from the parties to arrive at solutions that satisfy both parties. If a person's goal is simply to decide if one or two songs should be regularly included in the Sunday morning program, it will be much easier to come to a solution than if this person's goal is to determine a policy concerning song selection which takes into consideration both music's effects on the youth in the church and concerns about future building projects.

In summary, goals can be viewed as an individuals' internal representations of the states they desire. These goals are defined by the desired state, but are also characterized along several dimensions that are common to all goals and which greatly influence conflicts: importance, difficulty, specificity, temporal range, level of consciousness, and complexity.

Having defined conflict and goals, we will now examine the various streams of research relevant to understanding conflict goals.

\section{Conflict Motivation Models}

The first approach to understanding conflict goals focuses on understanding the motives of the parties in a conflict. These conflict motivation models can be classified as either one dimensional or two dimensional depending on the number of goal categories used to classify the goals that individuals are motivated to achieve.

\section{One Dimensional Models of Motivation}

The earliest motivational models of conflict behavior were developed by economists, assuming that parties simply wanted to maximize their outcomes (Nash, 1950; Schelling, 1960; Von Neumann et al., 1947). Based on game theory, these models assumed that all participants shared one unique economic goal or motive: to maximize their individual outcomes. These models describe 
theoretically what a smart and perfectly rational person should do in competitive situations (Raiffa, 1982). The value of these models is that they help determine the most rational thing to do in situations that may legitimately be modeled by purely quantitative outcomes (Dixit \& Nalebuff, 1993; Myerson, 1991). However, game theory provides little help for understanding actual humans, who are far from purely rational with unlimited intelligence (Raiffa, 1982; but for a contrary view of the value of game theory approaches, see Kelley et al., 2003).

An improvement over the one-goal-fits-all approach is the aspirations-level theory which assumes, while retaining only one dimension, that individuals have different levels of outcomes to which they aspire in a conflict (Siegel, 1957). This model allows for differences to be noted between individuals, whereas game theory assumes that all individuals have the same desire to maximize their outcomes. Nevertheless, all aspirations are still measured economically along one dimension. Many experiments have demonstrated that individuals with higher levels of aspiration, in general, obtain higher outcomes than those who aspire to lower levels (Zetik \& Stuhlmacher, 2002). However, the value of this approach is limited because conflict goals are assumed to be purely economic and do not take into consideration other goals that may influence conflict behavior (de Dreu, Weingart, \& Kwon, 2000).

An alternative one dimensional motivational model is cooperation and competition theory (Deutsch, 1973, 2000; Tjosvold, 1984, 1991). Rather than focusing on an economic motive or goal, this theory focuses on a person's social motives which are additive and can be placed along a one-dimensional axis. At one end of the axis (called the competitive motive), one party seeks to maximize his or her own outcomes in a conflict while minimizing the outcomes of the other party. At the other end (the prosocial motive), the party seeks to maximize both parties' outcomes in a conflict. At an in between position on the axis (called the egotistical motive), the party is concerned about its own outcomes, but is not concerned about the outcomes of the other party. The sum of a party's motives (concerning both parties' outcomes) determines how cooperative or competitive the party will be in a conflict. Parties with more prosocial motives tend to develop trust, exchange information constructively, and come up with solutions that have greater integrative potential, that is, the potential to respond to the concerns of both parties (Deutsch, 1958, 1973). Although this theory takes into consideration the degree of commitment that one has to helping the other party achieve its own goals (negative, neutral, or positive), the principle limitation of this approach is that one's commitment to one's own goals is not taken into account; commitment to one's own goals is assumed to be positive. In contrast, taking into account both of these dimensions (concern for other's goals and concern for self's goals) and treating them as two independent dimensions leads to significantly better predictions of conflict outcomes than does a single dimension (de Dreu et al., 2000); this approach is known as the dual concern model of conflict behavior (Pruitt \& Rubin, 1986).

\section{Two Dimensions of Motivation: The Dual Concern Model}

Based on two dimensional managerial and conflict response models of behavior (Blake \& Mouton, 1964; Thomas \& Kilmann, 1971), the dual concern model of conflict behavior (Pruitt \& Rubin, 1986) assumes that there are two primary motives in conflicts: concern for self and concern for other. Concern for self is similar to the dimension proposed by game theorists (Von Neumann et al., 1947) and the aspiration-level theories (Siegel, 1957); it is a measure of the degree to which one wants to accomplish his or her own goals, conceptually similar to the desire to maximize one's benefits in that the desired states are defined by self-interest. Concern for other is more relational in nature and is similar to the dimension proposed by cooperation and competition theory (Deutsch, 1973; Tjosvold, 1984); it is a measure of the degree that a person wants to maintain or develop a relationship with the other party or to provide the other party some benefit. These two motives function independently of each other, resulting in a four quadrant grid where each quadrant, according to the theory, predicts a different behavior.

The dual concern model (Pruitt \& Rubin, 1986; Rahim, 2001) makes several predictions. First, it predicts that the highest joint outcomes will occur when both parties are motivated by high concern for self and high concern for other. The model also predicts what behaviors are most likely given a person's concerns. When an individual is motivated by both high concern for self and high concern for other, he or she is most likely to respond to conflict with cooperation. Other combinations of concerns predict other conflict behaviors. An individual who is motivated by high concern for self and low concern for other will respond with competition. If the person is motivated by low concern for self and high concern for other, there will be accommodation, a giving in to the other party. If the person is motivated by both low concern for self and low concern for other, the conflict style is characterized by avoidance.

Good support has been found for most predictions of the dual concern model of conflict 
behavior. High concern for self and high concern for other generally leads to the highest joint outcomes (Ben-Yoav \& Pruitt, 1984; Rahim, 2001). Cooperation, competition, and accommodation are all predicted by the combinations of concerns posited by the theory; however, avoidance has not been able to be predicted by the combination of low concern for self and low concern for other (Sorenson, Morse, \& Savage, 1999). Nevertheless, in a meta-analysis of 28 studies comparing conflict theories (de Dreu et al., 2000), the dual concern model (two dimensions) has been shown to significantly account for conflict behavior better than cooperation and concern theory (one dimension). This result suggests that the dual concern model is a superior approach to describing conflict motives, at least for predicting conflict behaviors.

Although the dual concern model predicts several conflict behaviors, there appear to be other concerns or motivations that play a role in conflicts (Sorenson et al., 1999). For example, among the motivations for conflict avoidance (which is poorly predicted by the two dimensions of the dual concern model) are beliefs concerning the procedure used to make decisions (such as that the other party has the right or capacity to unilaterally make the decision), a desire to protect the relationship, ego protective concerns (to avoid a public or private attack), or the desire to work around the problem by "outflanking" the other (Tjosvold \& Sun, 2002). These goals are best addressed by other conflict models which are not limited to two dimensions of motivation.

\section{Models of Conflict Type}

Rather than identifying and measuring the motives of the conflict participants, another stream of conflict research deals with conflict goals by identifying characteristics of a conflict viewed as a whole. Two types of conflict were initially identified as "substantive" and "affective" conflict (Guetzkow \& Gyr, 1954). Modern researchers tend to call these task conflict and relationship conflict and call these categories conflict types (de Dreu \& Weingart, 2003; Desivilya \& Yagil, 2005; Jehn, 1995). Although these initial two categories of conflict may be similar to the two motives of concern for self and concern for other in the dual concern model of conflict behavior (Pruitt \& Rubin, 1986), they are characteristics of a conflict (within a group of two or more members), not of individual participants.

In any conflict, both task conflict and relationship conflict can be measured by asking parties to indicate the degree that various aspects of conflict are present in their situation (Jehn, 1995). Task conflict is indicated by the presence of disagreements about ideas and differences of opinions concerning how a task should be done. Relationship conflict is indicated by the presence of friction between the parties, tension in the relationship, and negative emotions. The value of these measures is that they predict different group outcomes. Relationship conflict predicts lower group performance, lower group satisfaction, and lower intent to remain in the group (Jehn, 1995, 1997b). Task conflict, in the absence of relationship conflict, predicts higher group performance in complex, nonroutine tasks (Jehn, 1995, 1997a). Relationship conflict is associated with negative affect, but task conflict (when controlling for relationship conflict) is not (Desivilya \& Yagil, 2005). Task conflict can have positive effects on group performance because it motivates group members to analyze problems in new ways and consider alternative solutions that otherwise may not be considered. Thus, task conflict will have positive consequences, especially if a group values comparing and contrasting various ideas concerning the accomplishment of a task (Jehn, 1997a; Turner \& Pratkanis, 1997).

The connection between conflict type and goals is clear. In task conflict, the goals of the participants concern the accomplishment of a group task. In relationship conflict, the goals of the participants concern the relationships and the interactions within the group. Both task conflict and relationship conflict can (and usually do) exist simultaneously in a given conflict (de Dreu \& Weingart, 2003).

Unlike the dual concern model, conflict type models are not limited to two categories of goals. Jehn (1997b) has proposed a third conflict type, process conflict, which is characterized by groups whose members experience responsibility disagreements, perceive pettiness on the part of others in the group, or believe that resources are allocated unfairly (Greer \& Jehn, 2007; Jehn, 1997b; Jehn \& Mannix, 2001). In process conflict, the goals of the participants are concerned with the process by which decisions are made or conflicts are resolved. Like relational conflict, process conflict predicts lower group performance and lower satisfaction with the group (Jehn, 1997b). It is also associated with negative affect; however, when group members are given voice and when other fairness concerns are addressed, the correlation becomes much weaker (Greer \& Jehn, 2007).

A fourth conflict type that has been recently proposed and examined is status conflict (Bendersky \& Hays, 2008). Status conflict is a measure of the degree to which members of a group try to assert dominance and compete for influence. The goals underlying status conflict involve power over group 
members. A recent study (Bendersky \& Hays, in press) demonstrated that in itself, status conflict is not necessarily associated with group performance; however it strongly interacts with task conflict in predicting group performance. In this study, task conflict was only a positive predictor of group performance when status conflict was low (Bendersky \& Hays, in press). When status conflict was high, the power struggle apparently negated any benefit that could come from task conflict.

Although conflict types (relationship, task, process, and status) predict group performance and satisfaction with conflict outcomes (i.e., how satisfied participants are with the results of the conflict process), they are also strongly critiqued. It can be argued that conflict types are arbitrary, both in their number and labeling (Tjosvold, 2008). Another critique concerns the predictive power of conflict types. Because task and relationship conflict are so strongly positively correlated, partialing out the effects of one conflict type is not especially meaningful. A meta-analysis (de Dreu \& Weingart, 2003) has demonstrated that relationship conflict (as well as task conflict) is a very good negative zeroorder predictor of task performance and group member satisfaction, not a positive predictor as it is when controlling for relationship conflict. In addition, the conflict typology approach has been criticized for stereotyping rational approaches to conflict as good (task conflict) and emotional reactions to conflict as bad (relationship conflict) when in reality both can be used to achieve positive results under certain conditions (Tjosvold \& Su, 2007; Tjosvold \& Sun, 2002).

Conflict types are useful for predicting conflict outcomes like group performance and participant satisfaction. At least four conflict types associated with various goals and outcomes have been identified: task, relationship, process, and status. These conflict types provide four categories which may describe conflict goals. However, there are still other approaches to understanding conflict goals which propose similar goal categories, but which provide a description of the goals of individuals, not a description of the conflict itself.

\section{Desired Outcomes}

This review has defined conflict as the process which begins when differences are perceived by the parties involved or opposition arises between these parties concerning something that is important to at least one of the parties. Latent conflict occurs within individuals and is characterized by a variety of perceptions and negative affect associated with opposition. As the two parties communicate, manifest conflict occurs as the parties seek to deal with the issues that concern them. This leads to the potential resolution of the conflict, if the issues and concerns are dealt with to dissipate the sources of latent conflict. If each party is aware of the concerns, interests, values, and desires (in short, the goals) of the other party, integrative solutions that address these goals can be more easily proposed than if one or both parties are unaware of them. The more a proposed solution addresses the concerns and desires of both parties, the more likely it is to be accepted by both parties (Fisher et al., 1991; Lewicki, Saunders, \& Barry, 2006; Ury, 1993). Therefore it is in the interest of conflict participants to know both their own goals and those of the other if they are concerned with maximizing joint outcomes.

In the process model of conflict described earlier (de Dreu \& Gelfand, 2008), the desires (which may be defined as conscious goals or interests) of each party may change as the conflict develops. This may be most easily seen in negotiations, a form of conflict characterized by a conversation between two parties as the principle means of communication (Pruitt \& Kim, 2004). If a buyer has an initial desire to pay a certain amount for a car, this desire may be modified if the dealer offers to include free oil changes or tickets to a ballgame in the proposed contract. The desired outcomes, or goals, may thus be categorized as prospective goals if the goals existed before the conflict began. Transactive goals are those that are activated during the manifest conflict (such as the possibility of tickets to a ballgame). Finally, retrospective goals develop after a period of manifest conflict that save face or provide justification for accepting a solution (Wilmot \& Hocker, 2001); for example, after buying a car and finding that the dealer was unscrupulous, the buyer might conclude that his or her original goal was to buy the car quickly and avoid unnecessary hassles. In most conflict episodes, these goals may exist simultaneously and overlap considerably (de Dreu \& Gelfand, 2008).

Although many conflict goals may be specific to the situation (e.g., not paying more than a certain sum for a car, receiving an apology from someone), some goals may be broad enough to be universally (or near universally) present in all individuals involved in conflicts (e.g., obtaining what one asks for, being treated with respect). Such hypothesized goals could vary in importance and specificity according to the individual and the circumstances, but they would be based on universal human concerns that are found in all conflictual situations. It is reasonable to believe that knowing that these universal goals exist and identifying their specific form could make it more likely for the parties to propose integrative solutions (solutions 
which take into account both parties' goals) and resolve the conflict satisfactorily. There are several streams of research that look for these universal goals held by individuals: goals in tactical communication (Dillard, 1990), interests versus positions (Fisher \& Ury, 1981; Wilmot \& Hocker, 2001), and subjective values in negotiations (Curhan et al., 2006). These three approaches will be classified together as desired outcome approaches because they all seek to identify the universal outcomes desired by all parties.

Goals in tactical communication. Research from a communications perspective has examined goals in tactical communications, situations where one person is trying to gain compliance from the other (Dillard, 1990). These goals are conceptually close to conflict goals in that they concern desired outcomes in conflictual situations. They have also been used outside the field of communications, in more psychologically oriented studies (Ohbuchi \& Tedeschi, 1997; Wang, Fink, Cai, \& Van Kleef, 2007). Beginning with a survey of tactics used to gain compliance from another person, Dillard (1990) asked a sample of students and business people to explain their goals, what they hoped to gain by using those tactics. A factor analysis revealed six families of goals. The first family included goals concerning the desire to persuade the other person to do or believe something; these were the primary goals concerning the other's compliance which an individual desired to gain. The other five families of self-reported secondary goals were a desire to maintain one's ethical standards, a desire to make a good impression on the other person, a desire to maintain a good relationship, a desire to avoid the other's hostility, and a desire to avoid feelings of anxiety. These goals were all found to be related to one's tactics in compliance gaining situations. For example, the tactical use of logic was positively associated with the goal of persuasion and the tactic of direct confrontation was negatively associated with the goal of avoiding feelings of anxiety.

Ohbuchi and Tedeschi (1997) extended this research by asking participants to recall a conflict episode and to rate the degree to which they held various goals. The goals in the list provided to the participants included those proposed by Dillard (1990), as well as some less socially desirable goals, such as the desire to hurt the other party. The participants were also asked to describe their conflict behaviors (tactics) in the recalled conflict episode, such as attempting to be friendly or using logical arguments. Ohbuchi and Teedischi proposed that conflict goals could be categorized as resource and social goals. Resource goals are the initial goals that precipitate the conflict. They characterize the content of the conflict and are relatively easy for the parties to identify. Social goals are activated during the conflict process, although they might exist beforehand in an unactivated, dormant form. Social goals may be further categorized as 1) those that are beneficial to relationships and lead to collaboration, and 2) those that are detrimental to the relationship and lead to aggression and competition. A factor analysis was performed on the strength of the participants' desire to achieve each of the aforementioned goals in the conflict they chose to describe. This factor analysis demonstrated that participants held separate resource and social goals. It also revealed four types of social goals:

Relationship goals: Wanting to maintain or improve the relationship with the other.

Power-hostility goals: Wanting to dominate and defeat the other.

Justice goals: Wanting to change the other's behavior so that the other shows more respect.

Identity goals: Wanting to restore honor, social face, or personal pride.

Apart from the relationship and power-hostility factors, these factors (goal categories) were reasonably orthogonal. In addition, some participants were found to hold multiple goals simultaneously (e.g. some participants might have both justice and identity goals in a conflict). As hypothesized, different goals predicted different tactics. Relationship goals predicted relationship enhancing tactics, while power-hostility goals and justice goals predicted more aggression and less relationship enhancing tactics; identity goals did not significantly predict the tactics chosen (Ohbuchi \& Tedeschi, 1997). Using this same approach of asking participants to indicate the presence and strength of their conflict goals from a list provided, it was also demonstrated that the strength of goals was influenced by culture, not just by individual differences (Ohbuchi, Fukushima, \& Tedeschi, 1999). Justice goals were more activated in individualist cultures than in collectivist cultures, while relationship goals were activated more in collectivist cultures.

This research program (Ohbuchi et al., 1999; Ohbuchi \& Tedeschi, 1997) contributes to understanding conflict goals in several ways. First, it demonstrates that individuals may hold multiple goals simultaneously, e.g. if a person reported having strong resource goals, he or she may also have reported strong identity goals. Second, it provides a new category of goals: power-hostility goals. Although these goals describe a desired relationship and the factor analysis indicates that the relationship and power-hostility factors are somewhat parallel and in opposite directions, power-hostility goals differ 
from relationship goals in that they are detrimental to the wellbeing of the other. Third, these studies demonstrate that the activation of conflict goals predicts conflict behavior in that different goals predicted different tactics for dealing with the conflict. Fourth, they demonstrate that culture influences the degree to which different conflict goals are activated in an individual.

Interests versus Positions. Perhaps the most influential research program in conflict management in the business world is that of Harvard Law School's Program on Negotiation (Fisher \& Ury, 1981; Hall, 1993). Fisher and Ury (1981) proposed that in negotiation and conflict resolution situations, negotiators should focus on interests, not positions. Interests are needs, concerns, or desires that each party values either consciously or unconsciously, whereas positions are specific proposals for solutions to resolve the conflict. The advantage of focusing on interests rather than positions is that they possess equifinality, that is, they are goals that may be achieved in any number of different ways, whereas positions are specific goals plus a specific means for achieving them, so they do not possess equifinality. Focusing on interests motivates negotiators to find integrative solutions that meet a broad range of both parties' interests, whereas focusing on positions emphasizes compromise and tends to focus on the economic or surface issues involved.

Fisher and Ury proposed that the most important interests (goals) were those associated with human need, proposing a tentative list strongly influenced by Maslow's $(1943,1962)$ hierarchy of needs: security, economic well-being, a sense of belonging, recognition, and control over one's life. They collapse this list into two basic categories: substantial and relational. These two categories are similar to the goals of task conflict and relationship conflict (de Dreu \& Weingart, 2003; Jehn, 1997b).

Seeking to develop a typology of interests, but using the same approach to classifying conflict goals as did Fisher and Ury (1981), that is, by trying to imagine all goals that interest humans, Lax and Sebenius (1986) propose two conceptually overlapping categories of interests beyond substantial interests and relationship interests. Process interests concern satisfying interactions between the parties; most often this would focus on respect and trust, but could also include the desire to dominate the other. Interest in principles involves interacting in ways that correspond to one's beliefs and values; this includes using norms of fairness to resolve conflicts and negotiations. Lax and Sebenius (1986) argue that fairness is a goal in conflicts in that people often (but not always) use principles of fairness to determine a range of acceptable resolutions (Schelling, 1960).

Seeking to reduce the conceptual overlap of goals in Lax and Sebenius' (1986) categorization of interests (especially the overlap in relationship interests and process interests with interest in principles), though admitting that they are not eliminated, Wilmot and Hocker (2001) proposed a similar set of conflict goals or interests which they identify by the acronym CRIP: content, relationship, identity, and process goals. Content goals concern the identifiable issues that are the focus of the conflict and are external to the parties in conflict. Relationship goals concern 1) the degree that the parties want to be interdependent (including the extent of influence they will have on each other) and 2) how the parties want to be treated by each other, usually with respect; these goals are usually known by the parties but are usually not mentioned. Identity goals concern 1) one's own face or public image (usually trying to save face), and 2) other's face or public image (often involving the desire to damage it when hostility is present). Process goals concern the communication processes that are involved in conflict resolution that influence how decisions are made. These goals may include desires concerning the role of authority and consensus in making a decision as well as desires concerning the timing and form of the communication processes. An important element in process goals is the question of voice, determining who will be able to express their point of view and the degree of importance that it will have.

The interests versus positions approach contributes to our understanding of the conceptual categories of conflict goals by clarifying the categories by which goals may be classified which may prove useful by giving us a framework to test. Such a classification lays the foundations for further hypothesizing and testing the existence of these goals (and perhaps various facets), how they relate to each other, and how they influence thoughts, feelings, behavior, and conflict outcomes. A deeper understanding of the effects of such conflict goals may permit conflicts to be handled more integratively, producing solutions that meet the goals of both parties.

Subjective Values in Negotiations. A third approach to desired outcomes in conflicts is the subjective values in negotiations approach (Curhan et al., 2006). In contrast to the deductive process of defining conflict goals in the interests versus positions approach (i.e., trying to imagine all the goals that interest humans), this approach is completely inductive, seeking to make no assumptions about what conflict goals exist, but to 
discover their existence empirically. In one study (Curhan et al., 2006), participants with diverse backgrounds were asked to think of several negotiation situations in which they had participated and to list everything that was important to them in the situations described (what they subjectively valued, conceptually similar to goals in that that both concepts express a desired state). Coders identified 20 relatively specific categories of what was subjectively valued by the negotiators. Experts (members of the Program on Negotiation at Harvard University) performed a sorting procedure and grouped the 20 categories into as many groups as they wanted (averaging about 7 groups) based on similarity. A matrix representing the conceptual distance of each of the 20 categories of desires was prepared from each expert's analysis and these matrices were used in both a cluster analysis and a factor analysis. Both analyses yielded four general factors that Curhan et al. described as feelings associated with various subjective values or goals. Feelings about the instrumental outcomes included desires about the objective settlement of the negotiation. Feelings about the self included saving face and doing what the participant believed was right. Feelings about the relationship included desires for trust and preserving the relationship. Feelings about the process included desires about emotional expressions during the negotiation, the desire to be understood, and the desire for fairness.

These four categories of what is subjectively valued have the advantage of having relatively little overlap with each other. Feelings about the relationship and feelings about the process were the closest of the factors, yet they remained distinct in a factor analysis used to confirm these four categories (Curhan et al., 2006). These categories are also valuable because they were derived from a bottom-up approach with no (or at least relatively few) assumptions as to what the goal categories should be, providing empirical justification for their use.

In spite of the difference in methods, there is little difference between Curhan et al.'s (2006) inductively and empirically derived categories and those derived by deductive, non-empirical approaches (Lax \& Sebenius, 1986; Wilmot \& Hocker, 2001). This provides important, confirmatory evidence that the goal categories proposed by the deductive approaches are justified.

However, there are several limitations of Curhan et al.'s (2006) study. First, only self-reported goals or desires were considered for inclusion. There were no goals reported that were not socially desirable (e.g., the desire to see the other party suffer or to exert power over the other party). In addition, only the goals that were accessible by introspection could be reported by the participants. Goals that did not become conscious could not be considered in this analysis and may thus be missing (Bargh et al., 2001).

We have examined several desired outcomes perspectives that have resulted in similar categories of conflict goals. The tactical communication perspective (Dillard, 1990; Ohbuchi \& Tedeschi, 1997) and subjective values in negotiation perspective (Curhan et al., 2006) sought to derive categories of goals from factor analyses of relatively exhaustive lists of conflict goals. The interests versus positions perspective (Fisher \& Ury, 1981; Lax \& Sebenius, 1986; Wilmot \& Hocker, 2001) produced several lists of conflict goals, all of which begin with the general notion of interests and conflict goals and then divide up the conflict goals into relatively distinct categories according to conceptual similarity. These general goal categories have also been confirmed empirically (Curhan et al., 2006). Because there are enough similarities in categorizations of goals that we have examined, we will now try to produce a synthesis, taking into consideration all of the approaches to conflict goals that we have considered.

\section{Synthesis}

Table 1 presents a synthesis of the three main approaches to identifying, classifying, and understanding conflict goals: the dual process model (Pruitt \& Rubin, 1986; Rahim, 2001), conflict types (Jehn, 1995,1997; Bendersky \& Hayes, in press), and the desired outcomes approaches. Four versions of the desired outcomes approach are presented: tactical communication (Ohbuchi \& Tedeschi, 1997), interests versus positions (Lax \& Sebenius, 1986), CRIP goals (Wilmot \& Hocker, 2001), and subjective values in negotiation (Curhan et al., 2006).

For all six of the approaches, the four principal goal categories are presented in Table 1. Although the vocabulary varies widely from model to model, many of the categories are conceptually similar and are placed on a row identified with a name which best captures the category, and identified with the same Roman numeral. For example, Row I identifies the goal category called concern for self, task, resource, substantial, content, or instrumental by the various approaches. This category is designated content because it best represents the common thread found across this category. The goals in this category all refer to the easily identified content of the conflict which tends to be the focus of the communication that occurs between parties. Row II contains relationship goals that concern how the parties want to relate and interact with one another. The goals in Row III primarily concern identity issues, how the 
parties want to be seen by themselves, by each other, or by any other people who might be observing them. The goals in Row IV concern the process by which the conflict is managed.

Some researchers have provided examples of subcategories of goals within the goal categories they have described. When clear descriptions of secondary classes of the goal categories have been proposed by researchers describing a desired outcomes model, subcategories are presented in Table 1 (Curhan et al., 2006; Wilmot \& Hocker, 2001). Similar subcategories, when they are classified under similar primary categories, are also placed in the same row in Table 1. For example, under Row IV Process, Curhan et al's (2006) concern for fairness is very similar to Wilmot and Hocker's (2001) concern for decision making rules because both are concerned with finding and enacting the appropriate principles by which the conflict will be resolved; these subcategories are both identified as IV.B in Table 1.

\section{The Four Principal Categories of Conflict Goals}

Although the comparison of the goal categories and their various subcategories presented in Table 1 is both subjective and tentative, there are several observations worth noting that have allowed such a classification to be made.

Content Goals. First, the goal category that is the most distinct is content, variously called concern for self, task, resource, substantial, content, or instrumental by the different streams of research (identified as Row I in Table 1). For all researchers, this category represents the most accessible surface level goals of the conflict which are the easiest for a party to identify in a conflict. This goal category concerns what the parties say they want and these goals serve as the basis of discussion because they are easily accessible with little or no introspection. Typically they concern the distribution of limited (or perceived limited) resources Although goals in this category may almost always appear with goals in other categories (de Dreu \& Weingart, 2003), conceptually this category is quite distinct, partially because this type of conflict goal is so easy for the parties to identify.

Relationship Goals. The second category of conflict goals is identified as Row II, relationship goals. Across the streams of research, this category of goals focuses on desired interpersonal processes and states involving the parties in conflict. On the positive side, these goals include maintaining or increasing interdependence, having agreeable interactions, or having self or other behave in certain ways, all of which imply, to some degree, a mutually beneficial relationship.

Yet relationship goals may also include states or behaviors which are not mutually beneficial. On the negative side of relationship goals, domination (Lax \& Sebenius, 1986) and power/hostility (Ohbuchi \& Tedeschi, 1997) have both been identified as conflict goals. Lax and Sebenius (1986) speculated that domination was an identity based goal. Ohbuchi and Tedeschi's (1997) factor analysis found separate factors for relationship goals and power/hostility goals, but the factors were negatively correlated. Because domination and power /hostility essentially describe specific relationship states, they are included in category II Relationship Goals in Table 1 instead of being placed in a separate category as they were in the original research. Nevertheless, there is some overlap of negative relationship goals with identity and process goals as will be discussed.

Identity Goals. The third category of conflict goals is identified as Row III, identity goals. These goals concern how the parties want to be perceived by themselves, by each other, or by parties external to the conflict. These goals may include saving face for self, saving face for the other party, or self-consistency in one's own behavior. Although they are social goals, they do not involve the interdependence associated with relationship goals (II). Rather, they are concerned with how one or the other party is perceived, whether favorably or negatively.

Conceptually, there is some overlap between identity goals (III) and relationship goals (II). If one party has a goal to protect or damage the other party's reputation, such a goal would likely be associated with a goal of enhancing or damaging the relationship between the two parties. Similarly, a person who values healthy relationships might have an identity goal of living consistently according to such values, which overlaps with the relationship goal of improving the quality of the relationship with the other party. Overlap such as this does not imply that goal categories are not conceptually distinct, but simply that a goal in one category may be similar to a goal in another category, so similar that at times these goals might be legitimately placed in both categories or viewed as single goal. In addition to conceptual overlap, more than one conflict goal can be activated in a given conflict (Ohbuchi \& Tedeschi, 1997) so that an actual overlap of multiple conflict goals may exist in an individual. This context dependent linkage further complicates attempts to place specific goals in a single, distinct category. 
Process Goals. The fourth category of conflict goals is identified as row IV, process goals. These are goals concerning the behavior of the two parties in the conflict process. People tend to desire the conflict process to be just and fair (Ohbuchi \& Tedeschi, 1997; Curhan, et al., 2006), to enable both parties to have a voice (Wilmot \& Hocker, 2001) and to follow an appropriate set of decision making rules (Wilmot \& Hocker, 2001).

The conceptual overlap between process goals and the other social goals may be substantial. The desire that interaction should be respectful among conflicting parties would be a process goal (IV), but it could also be part of Wilmot and Hocker's (2001) relationship goal subcategory of other's behavior toward self (II.B), as well as Curhan et al.'s (2006) relationship goal subcategory of self's behavior toward other (II.C). Similarly, the goal that self would act respectfully toward other could be an identity goal (III) as well as a process goal (IV). Thus the same goal may conceptually be, at the same time, a relationship, an identity, and a process goal.

Curhan et al. (2006) found that in their schema, process and relationship goals were more similar to each other than any other pair of social goal categories. This similarity, as well as the aforementioned conceptual overlap, indicates that the process goals may not be as distinct and well defined as the other goal categories.

Nevertheless, there are distinctions between process goals and the other social goals (relationship goals and identity goals). Whereas identity goals may concern intrapersonal processes (self's attitude toward self), process goals, as well as relationship goals, necessarily concern interpersonal interactions.

Similarly, relationship goals tend to concern habitual interpersonal interactions while process goals tend to concern interpersonal interactions that are contextually based within the conflict. The distinction between the two can be seen in that relationship goals would concern interpersonal processes that exist apart from the conflict (such as how the parties treat each other when discussing other topics) whereas process goals would concern interpersonal processes that exist wholly within the conflict. Relationship goals are more likely to be prospective goals (those which exist before the conflict is manifest), while process goals are more likely to be transactive goals (those that are activated during communication processes; Wilmot \& Hocker, 2001).

\section{Supracategories of Conflict Goals}

Content goals are distinct from the other categories of conflict goals in that the other categories are social in nature whereas content goals may only indirectly involve the other party. These other categories do not concern the resources which may lie at the surface of the conflict, but rather social elements which involve the other party. Because such a clear distinction exists between content goals and the other goal categories, two supracategories of conflict goals are proposed in Table 1, following Ohbuchi and Tedeschi's (1997) nomenclature. Content goals are placed in the supracategory of resource goals since they are concerned about the allocation and division of resources (whether concrete, like money, or abstract, like a position within an organization). The other goal categories are placed in the supracategory of social goals because they involve psychosocial phenomena involving both parties.

All of the conflict models presented in Table 1 propose conflict goals that are found in each of the supracategories. This is not the case for the four principal categories, as some research approaches do not include all of them (e.g., Jehn, 1997b; Pruitt \& Rubin, 1986). Goals found in both of these supracategories are found in all the models examined, providing further justification for the use of these supracategories.

\section{Conflict Goals: Areas of Further Research}

Having noted four broad categories of conflict goals in the conflict and negotiation literature, important questions remain about conflict goals, especially concerning the effect of attaining conflict goals. Researchers have found that a concern for both one's own goals and for the other party's goals predicts the highest joint outcomes for the parties in conflict and for the organization or team of which they are members (de Dreu et al., 2000; Rahim, 2001). However, little research has been done concerning how attaining (or not attaining) various goals affect individuals. This is an important question, both for better understanding how individuals respond to conflict and for learning how to better manage interpersonal conflict. Understanding how individuals respond to attaining (or not attaining) their goals in a conflict could be very useful in applied settings. This would enable people involved in conflicts (both the parties directly involved in conflict and any third parties who may be observing) to better understand the likely consequences that would occur if one or both parties attain or do not attain their goals. For example, in voluntary associations membership attrition is likely to occur if members are not sufficiently motivated to remain in an organization as in the case when personal goals are not attained (Etzioni, 1975; Harris, 1998; McPherson, 1981). Understanding the effects 
of goal attainment, or the lack thereof, could encourage the use of interventions which might lower the probability of the conflict having negative effects on the individuals or organization involved.

Variation of Conflict Goal Attainment. Several hypotheses can be made based on the current conflict goal literature. First of all, it is likely that goal attainment varies according to the situation. Individuals probably perceive that they attain their goals to a greater degree in some conflicts than in others, rather than perceiving their goal attainment in a binary fashion where the only perceptions would be "goal attained" or "goal not attained." This is an important issue because if an individual's perceptions of goal attainment do not vary according to the circumstance (e.g., goal satisfaction is a trait of individual, independent of the situation), studying the effects of goal attainment would have little practical application. Thus, the first hypothesis is proposed:

\section{$H_{1}$ : An individual's perceptions of goal attainment will vary according to the context.}

This hypothesis should be true for all types of goals: content, relationship, identity, and process.

If this hypothesis is supported, further studies of the effects of conflict goal attainment on individuals are justified.

\section{Conflict Goal Attainment and Behavior.} Another fundamental hypothesis concerns goal attainment and behavior. The degree to which people attain their conflict goals is likely to influence their behavior. For example, people who do not attain their goals in a conflict may be more likely to withdraw from a relationship or an organization than people who attain their conflict goals because they are less satisfied with the relationship or the organization. This leads to the second hypothesis:

\section{$\mathrm{H}_{2}$ : Perceptions of goal attainment will predict behavior.}

This hypothesis should be true for all types of goals: content, relationship, identity, and process.

This hypothesis is fundamental because if the degree to which different types of conflict goals are attained varies, but this variation does not predict behavior, then the relevance of conflict goal attainment may have little or no value in applied settings.

Conflict Goal Attainment and Conflict Resolution Satisfaction. If conflict goal attainment varies and predicts behavior, it is important to understand how it might affect satisfaction with the conflict resolution. In some cases, the resolution of the conflict will be viewed positively and in other cases it will be viewed negatively. Satisfaction with the conflict outcome is an important variable because satisfaction can predict behavior, such as attrition in organizations (Harman, Lee, Mitchell, Felps, \& Owens, 2007; Lee \& Mitchell, 1994) and the termination of relationships (Hendrick, Hendrick, \& Adler, 1988).

Because goals represent the desired outcomes in a conflict, it can be hypothesized that goal attainment will causally lead to satisfaction with the conflict outcome. Thus the third hypothesis is:

\section{$\mathrm{H}_{3}$ : Increased goal attainment will cause increased satisfaction with the conflict outcome.}

This hypothesis should be true for all types of goals: content, relationship, identity, and process.

If the above hypothesis is true, it is possible that resource goals (content goals) and social goals (relationship, identity, and process goals) interact. Resource goals tend to be the focus of conflict and likely influence the satisfaction that a party has with the outcome of the conflict. But it is possible that satisfaction may be moderated by the attainment of the more emotionally related social goals. Thus the interaction of resource and social goals may interact to contribute to an increase in satisfaction with the conflict outcome beyond the main effects of increased satisfaction due to attaining resource and social goals. This means that at low levels of social goal satisfaction (relationship, identity and process), there will be a small increase in conflict outcome satisfaction when resource goals (content goals) are satisfied. However, at higher levels of social goal satisfaction (relationship, identity, and process), there will be a larger increase in conflict outcome satisfaction.

Similarly, this interaction could be reconceptualized as its mathematical equivalent where the satisfaction coming from the attainment of social goals is moderated by the attainment of resource goals. At lower levels of resource goal satisfaction, there will be a small increase in goal satisfaction when social goals are satisfied. However, at higher levels of resource goal satisfaction, the satisfaction, there will be a larger increase in conflict outcome satisfaction.

On the other hand, the interaction might contribute to a decrease in satisfaction with the conflict outcome beyond the main effects of increased satisfaction due to attaining resource and social goals. In this case, the coefficient of the 
moderator term in a regression analysis would be negative, rather than positive. Thus the fourth hypothesis may be stated as:

\section{H4: There will be an interaction of resource and social goal attainment which contributes to predicting satisfaction with the conflict outcome beyond the main effects of attaining resource and social goals.}

This hypothesis could be true for all types of social goals, some of them, or none of them: relationship, identity, and process.

If this hypothesis is confirmed for any of the social goals, it will indicate which goals are the most important for individuals to achieve in various situations to maximize joint satisfaction. The parties involved in a conflict would have additional motivation to seek to manage the conflict in such a way that the most crucial categories of goals of the conflicting parties are addressed in order to yield the greatest joint satisfaction with the conflict outcomes.

The study of interpersonal conflict goals holds promise to help individuals and organizations better resolve the conflicts that concern them. Previous research has laid the foundation upon which future studies may build. New studies need to examine the effects of interpersonal conflict goal attainment on individuals, testing the hypotheses that have been proposed above. Such studies may lead to new information which may help people involved in conflicts find more satisfying outcomes to some of the most difficult situations that they encounter in life.

\section{References}

Austin, J. T., \& Vancouver, J. B. (1996). Goal constructs in psychology: Structure, process, and content. Psychological Bulletin, 120, 338-375.

Bargh, J. A., Gollwitzer, P. M., Lee-Chai, A., Barndollar, K., \& Trotschel, R. (2001). The automated will: Nonconscious activation and pursuit of behavioral goals. Journal of Personality and Social Psychology, 81, 1014-1027.

Ben-Yoav, O., \& Pruitt, D. G. (1984). Resistance to yielding and the expectation of cooperative future interaction in negotiation. Journal of Experimental Social Psychology, 20, 323-335.

Bendersky, C., \& Hays, N. (2008). The fourth dimension: Status conflict in groups. Paper presented at the IACM 21st Annual Conference, available at SSRN: $\mathrm{http}: / / \mathrm{ssrn} . \mathrm{com} / \mathrm{abstract}=1298494$.

Bendersky, C., \& Hays, N. (in press). Status conflict in groups. Organization Science.

Blake, R. R., \& Mouton, J. S. (1964). The managerial grid. Houston, TX: Gulf Publishing Company.
Coser, L. (1956). The functions of social conflict. Glencoe, IL: Free Press.

Curhan, J. R., Elfenbein, H. A., \& Xu, H. (2006). What do people value when they negotiate? Mapping the domain of subjective value in negotiation. Journal of Personality and Social Psychology, 91, 493-512.

de Dreu, C. K. W., \& Gelfand, M. J. (2008). Conflict in the workplace: Sources, functions, and dynamics across multiple levels of analysis. In C. K. De Dreu \& M. J. Gelfand (Eds.), The psychology of conflict and conflict management in organizations (pp. 3-54). New York, NY: Lawrence Erlbaum Associates.

de Dreu, C. K. W., \& Weingart, L. R. (2003). Task versus relationship conflict, team performance, and team member satisfaction: A meta-analysis. Journal of Applied Psychology, 88, 741-749.

de Dreu, C. K. W., Weingart, L. R., \& Kwon, S. (2000). Influence of social motives on integrative negotiation: A metaanalytic review and test of two theories. Journal of Personality and Social Psychology, 78, 889-905.

Desivilya, H. S., \& Yagil, D. (2005). The role of emotions in conflict management: The case of work teams. International Journal of Conflict Management, 16, 5569

Deutsch, M. (1958). Trust and suspicion. The Journal of Conflict Resolution, 2, 265-279.

Deutsch, M. (1973). The resolution of conflict: Constructive and destructive processes. New Haven, CT: Yale University Press.

Deutsch, M. (2000). Cooperation and competition. In M. Deutsch \& P. T. Coleman (Eds.), The handbook of conflict resolution (pp. 21-40). San Francisco, CA: Jossey-Bass.

Dillard, J. P. (1990). The nature and substance of goals in tactical communication. In M. J. Cody \& M. L. McLaughlin (Eds.), The psychology of tactical communication. Clevendon, UK: Multilingual Matters.

Dixit, A. K., \& Nalebuff, B. (1993). Thinking strategically: The competitive edge in business, politics, and everyday life. New York, NY: WW Norton \& Company.

Etzioni, A. (1975). A comparative analysis of complex organization: On power, involvement, and their correlates. (Rev. ed.). New York, NY: Free Press.

Fisher, R., \& Ury, W. (1981). Getting to yes: Negotiating agreement without giving in. Boston, MA: Houghton Mifflin.

Fisher, R., Ury, W., \& Patton, B. (1991). Getting to yes: Negotiating agreement without giving in. New York, NY: Penguin Books.

Greenhalgh, L. (1986). Managing conflict. Sloan Management Review, 27, 45-52.

Greer, L. L., \& Jehn, K. A. (2007). The pivotal role of negative affect in understanding the effects of process conflict on group performance. Research on managing groups and teams, 10, 23-45.

Guetzkow, H., \& Gyr, J. (1954). An analysis of conflict in decision-making groups. Human Relations, 7, 367-381.

Hall, L. (1993). Negotiation: Strategies for mutual gain: The basic seminar of the Harvard Program on Negotiation. Thousand Oaks, CA: Sage Publications.

Harman, W. S., Lee, T. W., Mitchell, T. R., Felps, W., \& Owens, B. P. (2007). The psychology of voluntary employee turnover. Current Directions in Psychological Science, $16,51-54$.

Harris, M. (1998). Doing it their way: Organizational challenges for voluntary associations. Nonprofit and Voluntary Sector Quarterly, 27, 144-158.

Hendrick, S. S., Hendrick, C., \& Adler, N. L. (1988). Romantic relationships: Love, satisfaction, and staying together. Journal of Personality and Social Psychology, 54, 980988. 
Jehn, K. A. (1995). A multimethod examination of the benefits and detriments of intragroup conflict. Administrative Science Quarterly, 40, 256-282.

Jehn, K. A. (1997a). Affective and cognitive conflict in work groups: Increasing performance through value-based intragroup conflict. In C. K. W. de Dreu \& E. Van de Vliert (Eds.), Using conflict in organizations. Thousand Oaks, CA: Sage Publications.

Jehn, K. A. (1997b). A quantitative analysis of conflict types and dimensions in organizational groups. Administrative Science Quarterly, 42, 530-557.

Jehn, K. A., \& Mannix, E. A. (2001). The dynamic nature of conflict: A longitudinal study of intragroup conflict and group performance. The Academy of Management Journal, 44, 238-251.

Katz, D., \& Kahn, R. L. (1966). The social psychology of organizations. New York, NY: John Wiley \& Sons.

Kelley, H. H., Holmes, J. G., Kerr, N. L., Reis, H. T., Rusbult, C. E., \& Van Lange, P. A. M. (2003). An atlas of interpersonal situations. Cambridge: Cambridge University Press.

Lax, D. A., \& Sebenius, J. K. (1986). Interests: The measure of negotiation. Negotiation Journal, 2, 73-92.

Lee, T. W., \& Mitchell, T. R. (1994). An alternative approach: The unfolding model of voluntary employee turnover. The Academy of Management Review, 19, 51-89.

Lewicki, R. L., Saunders, D. M., \& Barry, B. (2006). Negotiation (5th ed.). New York, NY: McGraw-Hill.

Lewin, K. (1948). Resolving social conflicts. New York, NY: Harper and Row.

Maslow, A. H. (1943). A theory of human motivation. Psychological Review, 50, 370-396.

Maslow, A. H. (1962). Toward a psychology of being. New York, NY: Van Nostrand.

McPherson, J. M. (1981). A dynamic model of voluntary affiliation. Social Forces, 59, 705-728.

Myerson, R. B. (1991). Game theory: Analysis of conflict. Cambridge, Mass.: Harvard University Press.

Nash, J. F. (1950). The bargaining problem. Econometrica, 18, 155-162.

Ohbuchi, K. I., Fukushima, O., \& Tedeschi, J. T. (1999). Cultural values in conflict management: Goal orientation, goal attainment, and tactical decision. Journal of CrossCultural Psychology, 30, 51-71.

Ohbuchi, K. I., \& Tedeschi, J. T. (1997). Multiple goals and tactical behaviors in social conflicts. Journal of Applied Social Psychology, 27, 2177-2199.

Olekalns, M., Putnam, L. L., Weingart, L. R., \& Metcalf, L. (2008). Communication processes and conflict management. In C. K. W. de Dreu \& M. J. Gelfand (Eds.), The psychology of conflict and conflict management in organizations. New York, NY: Lawrence Erlbaum Associates.

Pondy, L. R. (1967). Organizational conflict: Concepts and models. Administrative Science Quarterly, 12, 296-320.

Pruitt, D. G., \& Kim, S. H. (2004). Social conflict: Escalation, stalemate, and settlement (3rd ed.). Boston, MA: McGraw Hill.

Pruitt, D. G., \& Rubin, A. (1986). Social conflict: Escalation, stalemate, and settlement. New York, NY: Random House.

Rahim, M. A. (2001). Managing conflict in organizations (3rd ed.). Westport, CT: Quorum Books.

Raiffa, H. (1982). The art and science of negotiation. Cambridge, MA: Harvard University Press

Schelling, T. C. (1960). The strategy of conflict. Cambridge, MA: Harvard University Press.

Siegel, S. (1957). Level of aspiration and decision making. Psychological review, 64, 253-262.
Sorenson, R. L., Morse, E. A., \& Savage, G. T. (1999). A test of the motivations underlying choice of conflict strategies in the dual-concern model. International Journal of Conflict Management, 10, 25-44.

Steele, C. M. (1988). The psychology of self-affirmation: Sustaining the integrity of the self. In L. Berkowitz (Ed.), Advances in experimental social psychology (Vol. 21, pp. 261-302). San Diego, CA: Academic Press.

Thomas, K. W., \& Kilmann, R. H. (1971). Thomas-Kilmann conflict mode instrument. Tuxedo, NY: Consulting Psychologists Press.

Tjosvold, D. (1984). Cooperation theory and organizations. Human Relations, 37, 743-767.

Tjosvold, D. (1991). The conflict-positive organization. Reading, MA: Addison-Wesley.

Tjosvold, D. (2008). Conflicts in the study of conflicts in organizations. In C. K. W. de Dreu \& M. J. Gelfand (Eds.), The psychology of conflict management in organizations (pp. 445-453). New York, NY: Lawrence Erlbaum Associates.

Tjosvold, D., \& Su, F. (2007). Managing anger and annoyance in organizations in china: The role of constructive controversy. Group \& Organization Management, 32, 260-289.

Tjosvold, D., \& Sun, H. F. (2002). Understanding conflict avoidance: Relationship, motivations, actions, and consequences. International Journal of Conflict Management, 13, 142-164.

Turner, M. E., \& Pratkanis, A. R. (1997). Mitigating groupthink by stimulating constructive conflict. In C. K. W. de Dreu \& E. van de Vliert (Eds.), Using conflict in organizations (pp. 53-71). Thousand Oaks, CA: Sage Publications.

Ury, W. (1993). Getting past no: Negotiation your way from confrontation to cooperation (rev. ed.). New York, NY: Bantam Books.

Van de Vliert, E. (1997). Complex interpersonal conflict behaviour. Hove, UK: Pschology Press.

Von Neumann, J., Morgenstern, O., Kuhn, H. W., \& Rubinstein, A. (1947). Theory of games and economic behavior. Princeton, NJ: Princeton University Press.

Wang, Q., Fink, E. L., Cai, D. A., \& Van Kleef, G. (2007). A typology of interpersonal goals in conflict situations. Paper presented at the Annual Conference of the International Association for Conflict Management, Budapest, Hungary.

Wilmot, W. W., \& Hocker, J. L. (2001). Interpersonal conflict (6th ed.). Boston, MA: McGraw Hill.

Zetik, D. C., \& Stuhlmacher, A. F. (2002). Goal setting and negotiation performance: A meta-analysis. Group Processes and Intergroup Relations, 5, 35-52. 
Table 1

Synthesis of Conflict Goal Categories and Subcategories

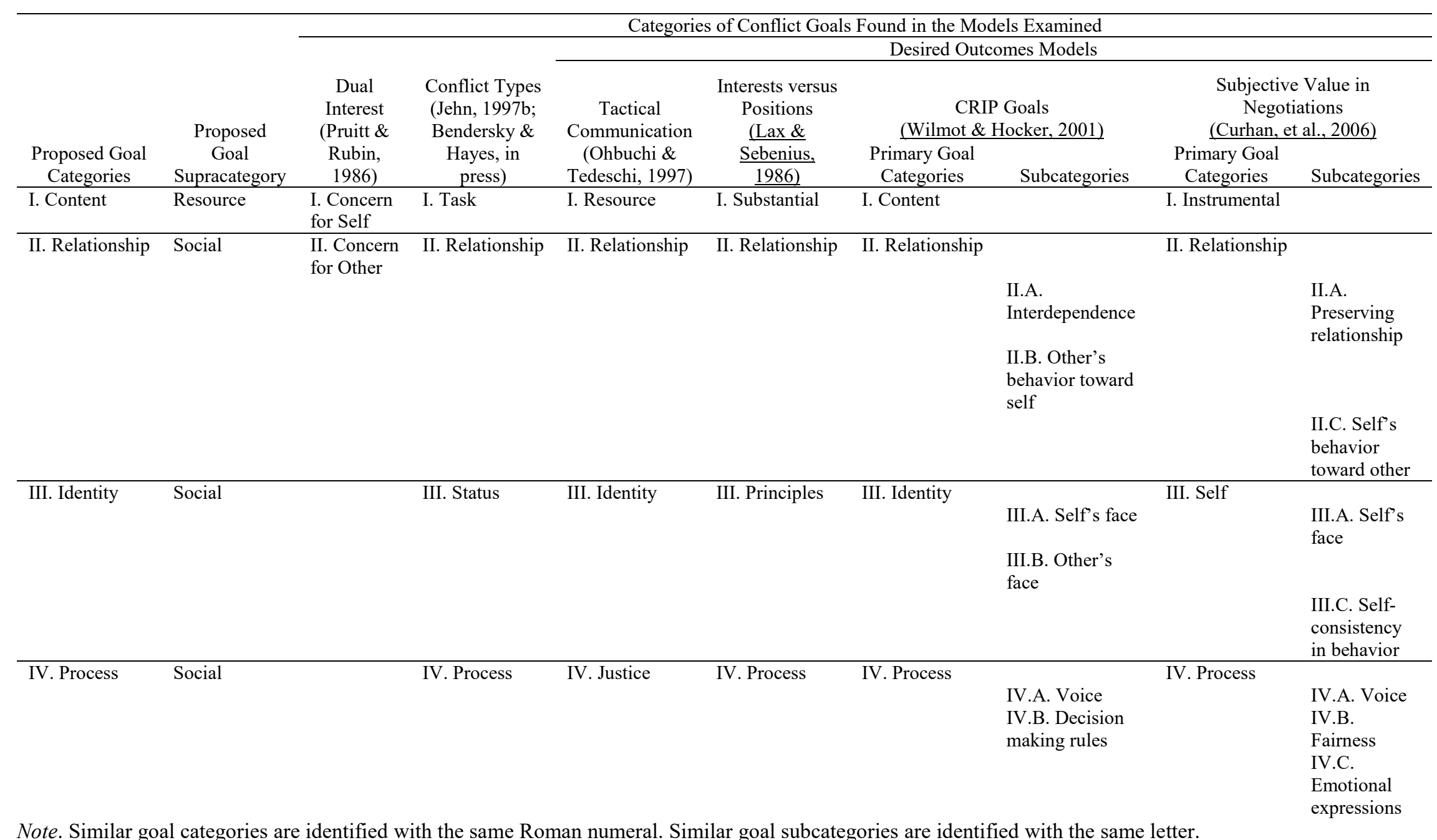

Note. Similar goal categories are identified with the same Roman numeral. Similar goal subcategories are identified with the same letter. 